\title{
Amylase Producing Bacillus megaterium T04 Isolated in Rach Lang Stream of Vietnam
}

\author{
Nguyen $\mathrm{Tu}^{*}$, Doan Vinh, Le Thu
}

Department of Biotechnology, School of Biotechnology, Hochiminh City International University, Vietnam national University-Hochiminh city, Quarter 6, Linh Trung Ward, Thu Duc District, Hochiminh city, Vietnam.

\begin{tabular}{l}
\hline ARTICLE INFO \\
\hline Article history: \\
Received on: $27 / 07 / 2015$ \\
Revised on: $15 / 08 / 2015$ \\
Accepted on: 06/09/2015 \\
Available online: $28 / 10 / 2015$ \\
\hline Key words: \\
Bacillus megaterium T04, \\
Rach Lang stream, starch \\
hydrolyzing ability, wheat \\
starch, rice starch. \\
\hline
\end{tabular}

\section{INTRODUCTION}

Microorganisms contribute to degradation of acid orange dye (Maulin et al., 2014), persistent insecticides (Selvanayagam and Vijaya, (1989), and are capable of metabolizing the herbicide metolachlor (Saxena et al., 2010). Microorganisms can produce many kinds of products such as lipase (Sekhon et al., 2003), poly (3-hydroxybutyrate) (Rodriguez-Contreras, 2013), potential proteins (Vary et al., 2007). Among their products, amylases are hydrolases than can breakdown or hydrolysis starch. Amylases can be applied in pharmaceutical fields (Kandra, 2003; Pandey, 2000). Amylases were produced in yeasts, molds, bacteria (Roopa and Sushma, 2013; Vihinen and Mantsala, 1989; Buzuhi and Martini, 2002). However, many previous studies showed that amylases produced in bacteria were more thermostable than fungal amylases (Omemu et al., 2009). Moreover, Bacillus strains were focused to produce amylases because they can grow quickly and require the simple nutrients for amylase production that could be benefit for a developing country. There was Bacillus subtilis IP 5832

\footnotetext{
* Corresponding Author

Nguyen Tu, Department of Biotechnology, School of Biotechnology, Hochiminh City International University, Hochiminh city, Vietnam. Email:nhktu@hcmiu.edu.vn
}

(Nataša et al., 2011) producing amylases in in shake flask and laboratory fermenter batch cultures. Bacillus sp. PN5 could produce a highly thermostable and alkaline amylase (Saxena et al., 2007). A moderately thermophilic Bacillus subtilis strain for starch processing was also studied (Asgher et al., 2007). Bacillus sp. IMD 435 produced the raw starch-digesting $\alpha$-amylase (Hamilton et al., 1999). Bacillus sp. I-3 could produce thermostable $\alpha$-amylase and its use in the direct hydrolysis of raw potato starch (Goyal et al., 2005). Bacillus caldolyticus produced $\alpha$-amylase in complex media (Schwab et al., 2009) while Bacillus licheniformis using an economical medium to produce $\alpha$-amylase. Amylase production in bacteria could be obtained under different conditions such as solid fermentation for B. amyloliquefaciens (Tanyildizi et al., 2007) and Bacillus cereus (Vijayabaskar et al., 2012). In this study, $B$. megaterium T04 was identified and determined the starch hydrolyzing ability due to find out a source for amylase production with high yield in simple nutrient.

\section{MATERIALS AND METHOD}

\section{Isolation and identification of starch hydrolyzing bacteria}

Rach Lang stream is a small stream belonging to Binh Thanh district, Hochiminh city, Vietnam), but it is polluted by many wastes containing cellulose, starches. Therefore, Rach Lang stream was thought as a source of amylase producing micro- 
organism. In this study, approximately $1 \mathrm{~L}$ of Rach Lang stream was collected and transferred to the lab. The stream samples were diluted in $0.9 \% \mathrm{NaCl}$ broth and then spread onto the ISP4 media supplemented with rice starch or wheat starch for starch hydrolyzing detection. No specific permit was required for the described field studies. Samples were incubated for 48 hours at room temperature. Then, colony showing the strong hydrozylation were selected for identification. The pure colony was identified by biochemical characterization based on the ability of the isolation to utilize different carbon sources, which determined by API 50CHB (bioMerieux, Lyon, France) and 16S rRNA sequencing analysis. Because of the purpose of the study was to isolate Bacillus megaterium, the primers should be specific to Bacillus megaterium. Therefore, the forward primer was Bal (5'AGTCGAGCGAACTGATTAGAAGCT -3') and the reverse primer was $\mathrm{Ba} \quad 2$ TACTCTCGTACTTGTCTTCCCTAACAACA-3'). The PCR reaction were performed as follows: $95{ }^{\circ} \mathrm{C}$ for $5 \mathrm{~min}$; 30 cycles of $95{ }^{\circ} \mathrm{C}$ for $20 \mathrm{~s}, 50{ }^{\circ} \mathrm{C}$ for $20 \mathrm{~s}$ and $72{ }^{\circ} \mathrm{C}$ for $3 \mathrm{~min}$; and a final extension at $72{ }^{\circ} \mathrm{C}$ for $10 \mathrm{~min}$. The PCR product was stored at $4{ }^{\circ} \mathrm{C}$. The PCR product was purified and sequenced. The homology comparison of the $16 \mathrm{~S}$ rRNA sequences was performed using the NCBI BLAST database.

\section{Starch hydrolyzing ability test \\ Sample preparation}

Cell free supernatant (CFS) of bacterial cultures in ISP4R and ISP4W medium at three temperatures $\left(25,37,45^{\circ} \mathrm{C}\right)$ in three incubation periods $(24,48,72$ hours) were assayed for their starch hydrolyzing ability. The CFS from cultures incubated at $37^{\circ} \mathrm{C}$ for 48 hours was chosen to assay the enzyme precipitation capability by ammonium sulfate precipitation method (Ammar, 2004). $50 \mathrm{~mL}$ of the CFS were added with ammonium sulfate to $40 \%$ saturation. The mixtures were centrifuged at $5000 \mathrm{rpm}$ for $15 \mathrm{~min}$ at $4{ }^{\circ} \mathrm{C}$ to collect the precipitated proteins. The pellets were dissolved in distilled water. The left supernatant was concentrated again with ammonium sulfate to $60 \%$ saturation. Each resulted fraction was assayed separately for its ability to hydrolyze starch.

\section{Starch hydrolyzing test}

Rice starch and wheat starch were used as substrates for the activity tests. Enzyme $\alpha$-amylase (Sigma) was used to make standard curve to represent the relation between the diameter of the halo zones and enzyme concentration. Ammonium sulfate was used to concentrate the enzyme. Lugol's iodine solution was used to visualize the clear zone through the formation of iodine-starch complex. Starch agar plate method was done to assay the starch hydrolyzing ability of Bacillus megaterium T04 (Farias et al., 2010). Rice starch containing agar plates (1\% rice starch) and wheat starch containing agar plates (1\% wheat starch) were used to detect the activities in $\mathrm{ISP}_{4 \mathrm{R}}$ and $\mathrm{ISP}_{4 \mathrm{~W}}$ medium respectively. Both CFS of Bacillus megaterium T04 cultures and ammonium sulfate fractions (in $40 \%$ and $60 \%$ saturation) were tested. The 11milimeter-in-diameter wells were made on the starch agar plates using sterile $11 \mathrm{~mm}$ cork borer. A volume of $300 \mu \mathrm{L}$ CFS was pipetted into each well. All the plates were placed overnight at room temperature. On the next day, they were stained with Lugol's iodine solution to visualize the halo diffusion zones. The results were recorded by observation and measurement the diameter of the halo zones (in $\mathrm{mm}$ ) around the wells. The same assay was performed to enzyme $\alpha$-amylase (Sigma) at different concentration (10 mg/mL, $5 \mathrm{mg} / \mathrm{mL}, 1 \mathrm{mg} / \mathrm{mL}, 0.1 \mathrm{mg} / \mathrm{mL}, 0.5 \mathrm{mg} / \mathrm{mL}$ ) to make a standard curve. The quantity of starch hydrolyzing enzyme in the testing samples could be estimated by basing on the standard $\alpha$ amylase curve (Farrias et al., 2010). All the tests were triplicated.

\section{Statistical analysis}

The data recorded were subjected to general linear model followed by post-hoc test using SPSS software version 16.0 to compare the means of starch hydrolyzing activities of CFS collected from the cultures in different conditions. The differences were considered as significant at $\mathrm{p}=0.05$.

\section{RESULTS \& DISCUSSION}

\section{Identification of starch hydrolyzing bacteria}

By biochemical test, bacterium showed positive results with glycerol, L-arabinose, D-xylose, galactose, D-glucose, Dfructose, inositol, mannitol and negative results with erythritol, Darabinose, L-xylose, adonitol, B-methylxyloside. Under microscope, the bacterium showed gram positive rod with vacuoles, and spore subterminals. By $16 \mathrm{~S}$ sRNA sequencing analysis, the starch hydrolyzing bacterium isolated in Rach Lang stream in Vietnam showed $99 \%$ homology to Bacillus megaterium QMB1551, named Bacillus megaterium T04 was deposited in DNA Data Bank of Japan (DDBJ) with accession number LC052666.

\section{Starch hydrolysis ability test \\ Effects of cultivation conditions}

The starch hydrolyzing abilities of the Bacillus megaterium T04 were studied in different cultivation conditions including two types of medium (ISP4R and ISP4W) in three levels of cultivation temperature $\left(25,37,45^{\circ} \mathrm{C}\right)$. Three cultivation periods $(24,48,72$ hours) were studied. The results of this study were shown in table 1 .

Table 1: Starch hydrolyzing abilities of Bacillus megaterium T04 in different conditions.

\begin{tabular}{lcc}
\hline $\begin{array}{c}\text { Cultivation condition } \\
\left.\text { (medium/ } /{ }^{\circ} \mathbf{C} / \mathbf{h r s}\right)\end{array}$ & \multicolumn{2}{c}{ Diameter of degradation zone (mm) } \\
\cline { 2 - 3 } & Mean & Standard deviation (SD) \\
\hline $\mathrm{ISP}_{4 \mathrm{R}} / 25^{\circ} \mathrm{C} / 24 \mathrm{~h}$ & 3.2 & 0.3 \\
$\mathrm{ISP}_{4 \mathrm{R}} / 25^{\circ} \mathrm{C} / 48 \mathrm{~h}$ & 4.8 & 0.6 \\
$\mathrm{ISP}_{4 \mathrm{R}} / 25^{\circ} \mathrm{C} / 72 \mathrm{~h}$ & 3.8 & 0.3 \\
$\mathrm{ISP}_{4 \mathrm{R}} / 37^{\circ} \mathrm{C} / 24 \mathrm{~h}$ & 4.8 & 0.3 \\
$\mathrm{ISP}_{4 \mathrm{R}} / 37^{\circ} \mathrm{C} / 48 \mathrm{~h}$ & 1.7 & 0.3 \\
$\mathrm{ISP}_{4 \mathrm{R}} / 37^{\circ} \mathrm{C} / 72 \mathrm{~h}$ & 5.3 & 0.6 \\
$\mathrm{ISP}_{4 \mathrm{R}} / 45^{\circ} \mathrm{C} / 24 \mathrm{~h}$ & 3.8 & 0.8 \\
$\mathrm{ISP}_{4 \mathrm{R}} / 45^{\circ} \mathrm{C} / 48 \mathrm{~h}$ & 3.8 & 0.6 \\
$\mathrm{ISP}_{4 \mathrm{R}} / 45^{\circ} \mathrm{C} / 72 \mathrm{~h}$ & 4.5 & 0.5 \\
$\mathrm{ISP}_{4 \mathrm{~W}} / 25^{\circ} \mathrm{C} / 24 \mathrm{~h}$ & 5.8 & 0.6 \\
$\mathrm{ISP}_{4 \mathrm{~W}} / 25^{\circ} \mathrm{C} / 48 \mathrm{~h}$ & 6.0 & 0.5 \\
\hline
\end{tabular}




\begin{tabular}{lll}
\hline $\mathrm{ISP}_{4 \mathrm{~W}} / 25^{\circ} \mathrm{C} / 72 \mathrm{~h}$ & 6.3 & 0.6 \\
$\mathrm{ISP}_{4 \mathrm{w}} / 37^{\circ} \mathrm{C} / 24 \mathrm{~h}$ & 5.8 & 0.3 \\
$\mathrm{ISP}_{4 \mathrm{~W}} / 37^{\circ} \mathrm{C} / 48 \mathrm{~h}$ & 8.7 & 0.3 \\
$\mathrm{ISP}_{4 \mathrm{~W}} / 37^{\circ} \mathrm{C} / 72 \mathrm{~h}$ & 6.3 & 0.6 \\
$\mathrm{ISP}_{4 \mathrm{~W}} / 45^{\circ} \mathrm{C} / 24 \mathrm{~h}$ & 2.5 & 0.5 \\
$\mathrm{ISP}_{4 \mathrm{~W}} / 45^{\circ} \mathrm{C} / 48 \mathrm{~h}$ & 6.2 & 0.6 \\
$\mathrm{ISP}_{4 \mathrm{~W}} / 45^{\circ} \mathrm{C} / 72 \mathrm{~h}$ & 5.3 & 0.3 \\
\hline
\end{tabular}

The results revealed that the Bacillus megaterium T04 could produce starch hydrolyzing enzyme in all assayed conditions of cultivation. By statistical analysis, there were significant effects of cultivation medium, incubation temperature and incubation time on the production of starch hydrolyzing enzyme of the Bacillus megaterium T04. Also, the interactions between these factors were shown significantly in all tests. The activities in all cases were shown in figure 1,2 , and 3 .

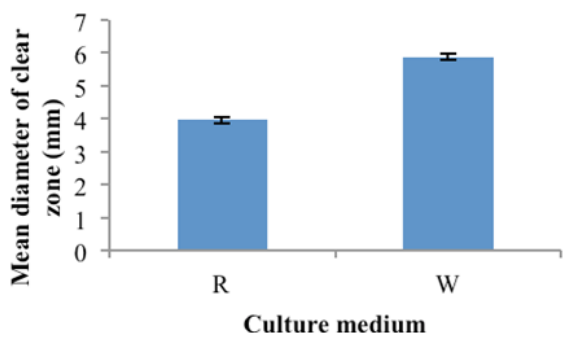

Fig. 1: Illustration for the comparison among different effects of two different media on starch hydrolyzing ability of Bacillus megaterium T04. R: $\mathrm{ISP}_{4 \mathrm{R}}$ medium, $\mathrm{W}: \mathrm{ISP}_{4 \mathrm{w}}$ medium.

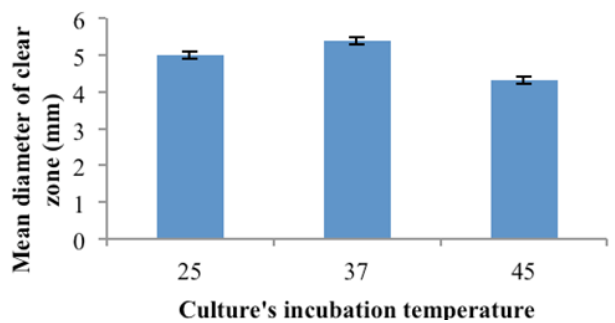

Fig. 2: Illustration for the multiple effects of different cultivation temperatures on starch hydrolyzing ability of Bacillus megaterium T04.

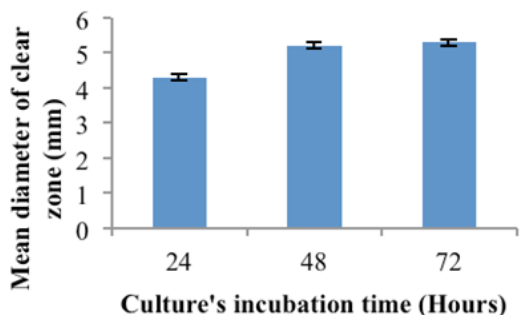

Fig. 3: Illustration for the multiple effects of different cultivation periods on starch hydrolyzing ability of Bacillus megaterium T04.

\section{Evaluation of ammonium sulfate fractionation}

Because the starch hydrolyzing ability was detected in CFSs of Bacillus megaterium T04 cultures, the follow-up step fractionation was done to try to recover as much as possible the starch hydrolysis enzymes from the cultures. CFSs from 48-hour cultures at $37^{\circ} \mathrm{C}$ in $\operatorname{ISP}_{4 \mathrm{R}}$ and $\operatorname{ISP}_{4 \mathrm{~W}}$ were concentrated by ammonium sulfate precipitation at $40 \%$ saturation and $60 \%$ saturation. The results were shown in the table 2 .
Table 2: Diameters of clear zones (mean SD, mm) and their equivalent $\alpha$ amylase concentration (mean $\mathrm{SD}, \mathrm{U} / \mathrm{mL}$ ) made by Bacillus megaterium $\mathrm{T} 04$ CFS (cultured at $37^{\circ} \mathrm{C}$ for 48 hours in ISP4R, and ISP4W medium) and their ammonium sulfate fractions (40\% and $60 \%$ saturation).

\begin{tabular}{|c|c|c|c|c|}
\hline 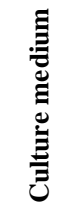 & 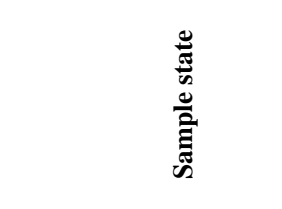 & 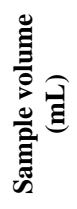 & 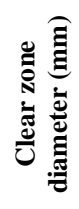 & 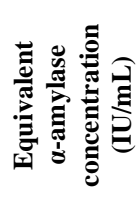 \\
\hline \multirow[t]{3}{*}{$\mathrm{ISP}_{4 \mathrm{R}}$} & Crude extract & 50 & 1.7 & 0.2 \\
\hline & $\begin{array}{l}\left(\mathrm{NH}_{4}\right)_{2} \mathrm{SO}_{4} \text { fractionation } \\
\text { (40\% saturation) }\end{array}$ & 2 & 0 & 0 \\
\hline & $\begin{array}{l}\left(\mathrm{NH}_{4}\right)_{2} \mathrm{SO}_{4} \text { fractionation } \\
(60 \% \text { saturation) }\end{array}$ & 2 & 1.8 & 0.2 \\
\hline \multirow{3}{*}{$\mathrm{ISP}_{4 \mathrm{~W}}$} & Crude extract & 50 & 8.7 & 174.7 \\
\hline & $\begin{array}{l}\left(\mathrm{NH}_{4}\right)_{2} \mathrm{SO}_{4} \text { fractionation } \\
\text { (40\% saturation) }\end{array}$ & 2 & 0 & 0 \\
\hline & $\begin{array}{l}\left(\mathrm{NH}_{4}\right)_{2} \mathrm{SO}_{4} \text { fractionation } \\
(60 \% \text { saturation) }\end{array}$ & 2 & 8.8 & 205.9 \\
\hline
\end{tabular}

There was no enzymatic activity detected in ammonium sulfate fractions at $40 \%$ saturation (Table 2, Figure 4, Figure 5). However, the ammonium sulfate fractions at $60 \%$ saturation expressed equal or higher enzymatic activity than the crude extracts (Table 2, Figure 4, Figure 5).

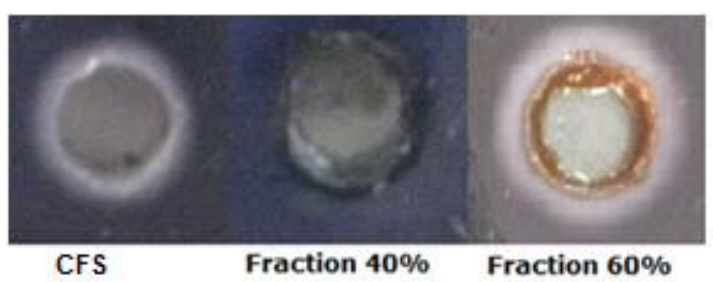

Fig. 4: Degradation zones produced by Bacillus megaterium T04 CFS and ammonium sulfate precipitation fractions of Bacillus megaterium T04 cultures in ISP4R medium at $37^{\circ} \mathrm{C}$ for 48 hours.

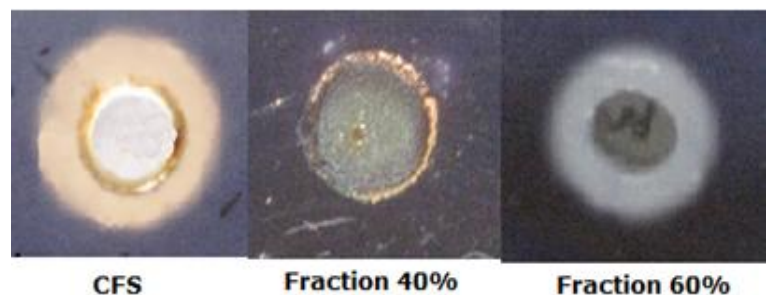

Fig. 51: Degradation zones produced by Bacillus megaterium T04 CFS, ammonium sulfate precipitation fractions of Bacillus megaterium T04 cultures in ISP4W medium, at $37^{\circ} \mathrm{C}$, for 48 hours

As seeing in the figure 4 and figure 5, the results of starch agar plate method to detect starch hydrolyzing ability of Bacillus megaterium T04 on different kinds of starch such as rice and wheat showed the similar hydrolysis phenomenon after ammonium sulfate precipitation (Figure 4 and Figure 5). Bacillus megaterium T04 revealed its starch hydrolyzing ability in all test conditions. Cultivation medium, incubation temperature, incubation time, and their interactions gave significant effects on this capability. It was because they affected to the growth and the metabolisms of the bacteria. Both rice starch and wheat starch in 
$\mathrm{ISP}_{4 \mathrm{R}}$ and $\mathrm{ISP}_{4 \mathrm{~W}}$ medium respectively were used as substrate for the growth of Bacillus megaterium T04. However, the difference in the composition of rice starch and wheat starch is the reason for the significant difference between the effects of $\mathrm{ISP}_{4 \mathrm{R}}$ and $\mathrm{ISP}_{4 \mathrm{~W}}$. Rice starch contains more amylopectin, which means that there were more $\alpha$-1,6-glycosidic linkages in rice starch than wheat starch. Reversely, more amylose in wheat starch indicates that there are more $\alpha-1,4$-glycosidic linkages in ISP4W than ISP4R. There were different enzymes responsible for starch hydrolysis. They are $\alpha$-amylase, $\beta$-amylase, glucoamylase, and pullulanase. Among them, $\alpha$-amylase and $\beta$-amylase only could hydrolyze starch by cutting $\alpha-1,4$-glycosidic linkages. Glucoamylase can hydrolyze starch by cutting both $\alpha-1,4$-glycosidic linkages and $\alpha$ 1,6-glycosidic linkages. Nevertheless, pullulanase can cut $\alpha-1,6-$ glycosidic linkages only (Hii et al., 2012). Interestingly, the enzyme showed $174.7 \mathrm{IU} / \mathrm{mL}$ and $0.2 \mathrm{IU} / \mathrm{mL}$ in medium containing wheat and rice, respectively. The activities of this enzyme produced by Bacillus megaterium T04 were higher than other Bacillus megaterium in the previous studies. The study pointed that Bacillus megaterium T04 amylase acted strongly in wheat starch that will be potential in pharmaceutical field and other applications, like brewing, environmental areas.

In the effort to recover the starch hydrolyzing enzymes produced by Bacillus megaterium T04, fractions of $40 \%$ ammonium sulfate didn't present activity, whereas fractions of $60 \%$ ammonium sulfate precipitation showed activities. It confirmed the protein nature of the starch hydrolyzing agents produced.

\section{CONCLUSION}

The starch hydrolyzing ability was detected in CFSs from cultures of Bacillus megaterium T04 cultured in $\mathrm{ISP}_{4 \mathrm{R}}$ and $\mathrm{ISP}_{4 \mathrm{~W}}$ medium. Both rice starch and wheat starch can be used as the substrates to induce Bacillus megaterium T04 to produce starch hydrolyzing enzymes. These biological activities of this strain were found in the cultures up to 72-hour-old and at incubation temperature up to $45^{\circ} \mathrm{C}$. These results showed the potentials to produce starch hydrolyzing enzyme in cheap media of $\mathrm{ISP}_{4 \mathrm{w}}$.

\section{REFERENCES}

Asgher M, Asad MJ, Rahman SU and Legge RL. A thermostable $\alpha$-amylase from a moderately thermophilic Bacillus subtilis strain for starch processing. J Food Eng, 2007; 79(3): 950-955.

Buzuhi and Martini. Extracellular enzymatic activity profiles in yeast and yeast like strains isolated from tropical environments. J Appl Microbiol, 2002; 93: 1020-1025.

Farias DF, Carvalho AFU, Oliveira CC, Sousa NM, RochaBezerrra LC B, Ferreira PMP and Hissa DC. Alternative method for quantification of alfa-amylase activity. Braz J Biol, 2010; 70(2): 405-407.

Goyal N, Gupta JK and Soni SK. A novel raw starch digesting thermostable $\alpha$-amylase from Bacillus sp. I-3 and its use in the direct hydrolysis of raw potato starch. Enzyme Microb Tech, 2005; 37(7): $723-$ 734.

Hamilton LM, Kelly CT and Fogarty WM. Production and properties of the raw starch-digesting $\alpha$-amylase of Bacillus sp. IMD 435. Process Biochem, 1999; 35 (1-2): 27-31.
Haq IU,Ashraf H,Iqbal J and Qadeer MA. Production of alpha amylase by Bacillus licheniformis using an economical medium. Bioresource Technol, 2003; 87(1): 57-61.

Hii SL, Tan JS, Ling TC, and Ariff AB. Pullulanase: role in starch hydrolysis and potential industrial applications. Enzyme research, 2012; 2012. Article ID 921362, 14 pages, 2012. doi:10.1155/2012/921362

Kandra L. $\alpha$-amylases of medical and industrial importance. J Mol Struc -Theochem, 2003; 666-667: 487-498.

Maulin PS. Bioremedial application of Bacillus megaterium PMS82 in microbial degradation of acid orange dye. Int J Biometeorol, 2014; 2(3): 93-99.

Nataša $\mathrm{B}$, Jordi R, Josep L and Zoran V. Optimization of the growth and $\alpha$-amylase production of Bacillus subtilisIP 5832 in shake flask and laboratory fermenter batch cultures. J Serb Chem Soc, 2011; 76 (7): 965-972.

Omemu AM, Akpan I, Bankole MO and Teniola OD. Hydrolysis of raw tuber starches by amylase of Aspergillus niger AM07 isolated from the soil. Afr J Biotechnol, 2005; 4: 19-25.

Oyeleke and Oduwole. Production of amylase by bacteria isolated from a cassava dumpsite in minna, Niger state, Nigeria. Afr J Microbiol Res, 2009; 4(3): 143-146.

Pandey A, Nigam P, Soccol CR, Soccol VT, Singh D and Mohan R. Advances in microbial amylases. Biotechnol Appl Bioc, 2000; 31(2): 135-152.

Rodriguez-Contreras A, Koller M, Miranda-de Sousa Dias M, Calafell-Monfort M Braunegg G and Marques-Calvo MS. High production of poly (3-hydroxybutyrate) from a wild Bacillus megaterium Bolivian strain. J Appl Microbiol, 2013; 1-10.

Saxena RK, Dutt K, Agarwal L and Nayyar P. A highly thermostable and alkaline amylase from a Bacillus sp. PN5. Bioresource Technol, 2007; 98(2): 260-265.

Saxena A, Zhang RW and Bollag JM. Microorganism: capable of metabolizing the herbicide metolachlor. Appl Enviror Microbiol, 1987; 53: 390-396.

Schwab K, Bader J, Brokamp C, Popović MK, Bajpai R and Berovič M. Dual feeding strategy for the production of $\alpha$-amylase by Bacillus caldolyticus using complex media. New Biotechnol, 2009; 26(12): $68-74$.

Sekhon A, Dahiya N, Tewari PR and Hoondal SG. Production of extracellular lipase by Bacillus megaterium AKG-1 in submerged fermentation. Indian J Biotechnol, 2006; 5:179-183.

Selvanayagam $\mathrm{M}$ and Vijaya J. Degradation of persistent insecticides by aquatic bacteria as sole source of carbon. J Enviro.Biol, 1989; 10: 399-407.

Tanyildizi MS, Özer D and Elibol M. Production of bacterial $\alpha$ amylase by Bacillus amyloliquefaciens under solid substrate fermentation. Biochem Eng J, 2007; 37(3): 294-297.

Vary PS, Biedendieck R, Fuerch T, Meinhardt F, Rohde M, Deckwer WD, Jahn D. Bacillus megaterium - from simple soil bacterium to industrial protein production host. Appl Microbiol Biot, 2007; 76(5): 957-967.

Vihinen M and Mantsala P. Microbial amylolytic enzymes. Crit Rev Biochem Mol, 1989; 24: 329-418.

Vijayabaskar P, Jayalakshmi D and Shankar T. Amylase production by moderately halophilic Bacillus cereus in solid state fermentation. Afr J Microbiol Res, 2012; 6: 4918-4926.

\section{How to cite this article:}

Nguyen Tu, Doan Vinh, Le Thu. Amylase Producing Bacillus megaterium T04 Isolated in Rach Lang Stream of Vietnam. J App Pharm Sci, 2015; 5 (10): 012-015. 